\title{
Isolation method and xeno-free culture conditions influence multipotent differentiation capacity of human Wharton's jelly-derived mesenchymal stem cells
}

\author{
Maria Cristina Corotchi ${ }^{1+}$, Mirel Adrian Popa ${ }^{1+}$, Anca Remes $^{1}$, Livia Elena Sima ${ }^{2}$, llinca Gussi ${ }^{3}$ \\ and Marilena Lupu Plesu ${ }^{*}$
}

See related commentary by Crisan, http://stemcellres.com/content/4/4/95

\begin{abstract}
Introduction: Human Wharton's jelly (WJ) has become a preferred source of mesenchymal stem cells (MSCs) whose clinical applications are limited by the use of adequate xeno-free (XF), in vitro manipulation conditions. Therefore, the objective of our study was to characterize WJ-derived MSCs (WJ-MSCs), isolated by different methods and cultured in a commercially available, MSC XF medium, not least of all by investigating their endothelial differentiation capacity.

Methods: WJ explants and enzymatically dissociated WJ cells were cultured in a defined, XF medium for MSCs. Adherent cells at passages 2 and 5 were characterized as MSCs by flow cytometry, MTT, real-time quantitative reverse transcription PCR, and functional multipotent differentiation assays. The endothelial differentiation capacity of MSCs isolated and expanded until passage 2 in the MSC XF medium, and then subcultured for five passages in a commercially available endothelial growth medium (group A), was assessed over serial passages, as compared to adherent WJ-derived cells isolated and expanded for five consecutive passages in the endothelial medium (group B).

Results: The MSC phenotype of WJ explant- and pellet-derived cells, isolated and expanded in the MSC XF medium, was proven based on the expression of CD44/CD73/CD90/CD105 surface markers and osteo-/adipo-/chondrogenic multipotent differentiation potential, which differed according to the isolation method and/or passage number. Upon exposure to endothelial differentiation cues, cells belonging to group A did not exhibit endothelial cell characteristics over serial passages; by contrast, WJ pellet-derived cells belonging to group B expressed endothelial characteristics at gene, protein and functional levels, potentially due to culture conditions favoring the isolation of other stem/progenitor cell types than MSCs, able to give rise to an endothelial progeny.

Conclusions: The use of defined, MSC XF media for isolation and expansion of human WJ-MSCs is a prerequisite for the establishment of their real endothelial differentiation capacity, as candidates for clinical therapy applications. Thus, the standardization of WJ-MSCs isolation and culture expansion techniques in defined, MSC XF media, for their accurate characterization, would be a priority in the stem cell research field.
\end{abstract}

Keywords: Wharton's jelly, Mesenchymal stem cells, Xeno-free medium, Plasticity, Endothelial differentiation

\footnotetext{
* Correspondence: marilena.lupu@icbp.ro

${ }^{\dagger}$ Equal contributors

${ }^{1}$ Angiogenesis and Cardiovascular Remodeling Group, Department of

Regenerative Medicine, Institute of Cellular Biology and Pathology

"Nicolae Simionescu" of the Romanian Academy, 8 B.P. Hasdeu Str., 050568,

Bucharest, Romania

Full list of author information is available at the end of the article
} 


\section{Introduction}

Among multiple sources of stem cells, human umbilical cord matrix, namely, Wharton's jelly (WJ), has recently become the preferential source of stem cells, including mesenchymal stem cells (MSCs), because of rapid availability with a large donor pool, non-invasive collection with no risk or discomfort for the donor, no ethical constraints, high in vitro expandable rates and multipotent differentiation potential [1-7]. Due to proven immunomodulatory effects, WJ-derived MSCs (WJ-MSCs) are now considered attractive agents not only for autologous, but also for allogeneic cell therapy approaches of malignant and non-malignant, hematopoietic and nonhematopoietic, inherited and acquired diseases $[1,8,9]$.

Whereas adult bone marrow (BM)-derived MSCs (BM-MSCs) have shown limited therapeutic benefits for organ regeneration, it has been postulated that WJderived primitive stromal cells are a valuable alternative source of cells that possess multipotent properties between embryonic and adult stem cells [2,10-12]. WJMSCs have a higher proliferation rate $[13,14]$ and a higher expression level of early endodermal markers, as well as undifferentiated human embryonic and pluripotent/stem cell markers, both at early and late passages [12]. Although WJ-MSCs share common surface markers with BM-MSCs, such as the immunomodulatory molecules $[4,15]$, they are endowed with superior plasticity properties [3]. Furthermore, it has been shown that the immune privilege exerted by WJ-MSCs is also maintained in the differentiated adipogenic, osteogenic and chondrogenic progeny [5].

Generation of an endothelial cell outgrowth from the matrix of the umbilical cord, for vascular regeneration purposes, has been described by several groups [13,16-19]; however, the applied differentiation protocols did not involve the use of a defined MSC medium for WJ-MSCs isolation prior to their seeding into endothelial differentiation media, raising the question of potential contamination of the generated cultures with other stem cell types able to give rise to an endothelial progeny, circulating endothelial progenitor cells or mature endothelial cells.

Several groups have established various protocols for the isolation and characterization of stromal cells from WJ $[11,18,20-23]$. However, the effects of defined, xenofree (XF) media, designed for MSCs isolation and expansion, on the gene, protein and functional profiles of WJ-MSCs have not been thoroughly investigated. It has been shown that XF culture systems allow for better multipotent differentiation and/or expansion rates of adipose tissue- and BM-MSCs, serving as a preferred alternative to fetal bovine serum (FBS)-containing media for the production of large scale, functionally competent, clinical grade MSCs [24-26]. In addition, the use of FBS for MSCs in vitro isolation and expansion raises concerns for the transmission of zoonoses and induction of immunogenic reactions after clinical transplantation, due to xenogeneic proteins transmitted from FBS to MSCs during culture $[27,28]$. Therefore, the in vitro manipulation of MSCs by using XF culture conditions before clinical applications has become an important step in order to yield homogenous cell populations with self-renewal and multi-lineage differentiation potential, but without an increase in chromosome aberrations.

Despite a wide range of potential clinical applications, such as for bone [29], cartilage [30], musculoskeletal $[31,32]$ and nerve [33] regeneration, for the treatment of liver fibrosis [10,34] and type 1 diabetes [35], as well as for heart valve [36] and vocal fold reconstruction [37], WJ-MSC populations isolated in defined, XF conditions have not been fully characterized. Therefore, given their particular plasticity and developmental flexibility, the impact of XF conditions on functional properties of umbilical cord stromal cells deserve to be thoroughly examined. To elucidate the real value of WJ-MSCs for clinical cell replacement therapy, further work is thus needed in order to determine whether these cells, isolated and expanded in defined, XF media, truly express differentiation capabilities beyond the canonical plasticity towards the adipogenic, osteogenic and chondrogenic cell lineages [38].

To get further insights into the biology of WJ-derived cells, the objectives of our study were to isolate, by using different protocols, and expand human WJ-MSCs in a commercially available, XF medium, selective for MSCs, and to characterize them at gene, protein and functional levels, not at the least by determining their endothelial differentiation capacity.

\section{Methods \\ MSCs isolation}

Human umbilical cord samples were collected following term deliveries at the Department of Obstetrics and Gynecology, "Dr. I. Cantacuzino" Hospital, Bucharest, Romania. The samples were obtained upon written informed consent from mothers and complied with European Union and national legislation regarding human samples collection, manipulation and personal data protection. All samples were tested for the absence of HIV, HBV and HCV and processed within three hours of collection.

WJ was isolated from the umbilical cords after dissection and removal of the umbilical cord arteries, vein and amniotic epithelium. MSCs isolation from WJ was achieved either by mechanical dissociation for generation of tissue explants of approximately $2 \mathrm{~mm}^{2}$, or by enzymatic dissociation with collagenase I and hyaluronidase (Sigma-Aldrich, St. Louis, MO, USA) for generation of WJ cell pellets. Tissue explants and suspended cell 
pellets were thereafter seeded onto tissue cultured dishes (10 tissue explants/dish) and flasks $\left(5 \times 10^{5}\right.$ cells/flask), respectively, pre-coated with $\mathrm{MesenCult}^{\mathrm{Tm}}-\mathrm{XF}$ Attachment Substrate, in MesenCult ${ }^{\mathrm{Tm}}-\mathrm{XF}$ Complete medium (XF medium), consisting of MesenCult ${ }^{\mathrm{TM}}-\mathrm{XF}$ Basal medium supplemented with $20 \%$ MesenCult $^{\mathrm{Tm}}$-XF Proliferation Supplement (all from STEMCELL Technologies ${ }^{\mathrm{TM}}$ Inc., Vancouver, BC, Canada), L-Glutamine to a final concentration of $2 \mathrm{mM}, 100 \mathrm{U} / \mathrm{ml}$ penicillin, $100 \mu \mathrm{g} / \mathrm{ml}$ streptomycin and $50 \mu \mathrm{g} / \mathrm{ml}$ neomycin (all from SigmaAldrich). Cultures of both WJ tissue explants and suspended cell pellets were maintained at $37^{\circ} \mathrm{C}$ with $5 \% \mathrm{CO}_{2}$ and $21 \% \mathrm{O}_{2}$ in a humidified atmosphere. For optimal cell growth, medium was changed at the moment of subculture or, if the medium appeared acidic prior to cells reaching $80 \%$ confluence, half-medium change was performed. For the purpose of subculturing, the cells were enzymatically-detached using the MesenCult ${ }^{\mathrm{TM}}$ Dissociation Kit (STEMCELL Technologies ${ }^{\mathrm{Tm}}$ Inc.). Cells from passages (P) 2 and 5 were used for cell characterization experiments (see Figure 1 describing the experimental design). Five WJ explant-derived and eight WJ pelletderived MSC populations were isolated and expanded in the XF medium until P5 for the proposed experiments. All procedures were approved by the Ethical Committee Board of the Institute of Cellular Biology and Pathology "Nicolae Simionescu", Bucharest.

\section{Cells characterization}

\section{Proliferation assays}

Morphological characterization of cells was done by light microscopy, using an inverted epifluorescence microscope
(Eclipse TE300, Nikon, Tokyo, Japan) and a digital camera system for imaging (Digital Net Camera DN100, Nikon). Viability and proliferation of WJ explant- and pelletderived MSC populations $(n=5)$ at P2 were evaluated using a modified colorimetric 3-(4,5-dimethylthiazol-2yl)-2,5-diphenyltetrazolium bromide (MTT) assay method (CellTiter96 Non-Radioactive Cell Proliferation Assay, Promega, Madison, WI, USA), according to the manufacturer's instructions. Cells were seeded in 96-well plates at a density of $3 \times 10^{3}$ cells/well in the XF medium. The assay was performed every 24 hours during a two-week period, in triplicates. The absorbance was measured at a wavelength of $570 \mathrm{~nm}$ by using a spectrophotometric plate reader (Mithras LB 940, Berthold Technology, Bad Wildbad, Germany).

\section{Adipogenesis, osteogenesis and chondrogenesis assays}

In vitro differentiation potential of WJ explant- and pelletderived MSC populations $(n=5)$ at P2 and P5 into adipogenic, osteogenic and chondrogenic lineages was assessed by using specifically formulated cell culture media (MesenCult $^{\mathrm{Ts}}$ Adipogenic Stimulatory Supplements-Human and MesenCult ${ }^{\mathrm{TM}}$ Osteogenic Stimulatory Kit-Human from STEMCELL Technologies ${ }^{\mathrm{TM}}$ Inc., as well as StemMACS ChondroDiff Media-Human from Miltenyi Biotec $\mathrm{GmbH}$, Bergisch Gladbach, Germany), and the manufacturer's guidelines.

Briefly, for adipocyte and osteocyte differentiation, MSCs were plated at a density of $12.5 \times 10^{3}$ cells $/ \mathrm{cm}^{2}$ and $5 \times 10^{3}$ cells $/ \mathrm{cm}^{2}$, respectively, in six-well cell culture plates and kept in normoxic conditions for two and four weeks, respectively, with medium changed every

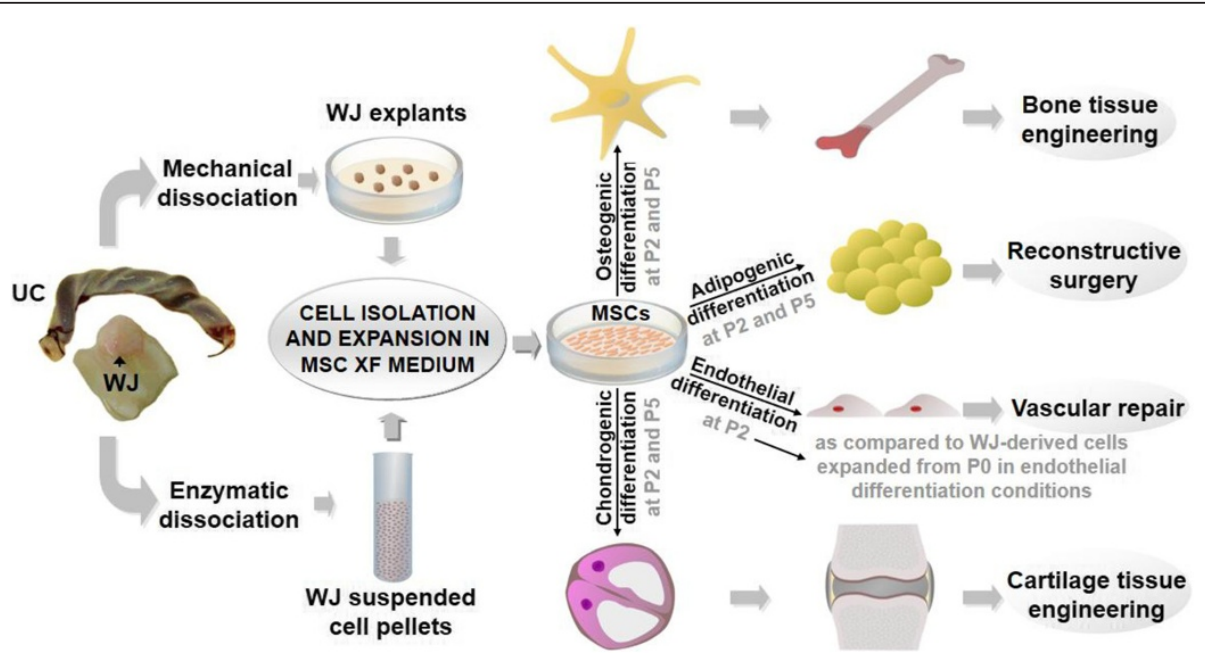

Figure 1 Experimental design. Isolation and expansion of MSCs, derived from WJ explants and enzymatically dissociated WJ, in a XF medium defined for MSCs, followed by their characterization, not the least by investigating their osteogenic, chondrogenic, adipogenic (at P2 and P5) and endothelial differentiation capacity (at P2, as compared to WJ-derived cells expanded from P0 in endothelial differentiation conditions), for use in different clinical settings of regenerative and reconstructive medicine [13,16-19,29,30,39]. MSCs, mesenchymal stem cells; P, passage; UC, umbilical cord; WJ, Wharton's jelly; XF, xeno-free. 
three days. Adipogenic differentiation was verified by staining with Oil Red O (0.5\% in isopropanol) and osteogenic differentiation was visualized by Alizarin Red $S$ ( $2 \%$ in distilled water) staining (both from SigmaAldrich). To these purposes, cells were fixed with a $4 \%$ paraformaldehyde solution in $1 \mathrm{x}$ phosphate-buffered saline (PBS) for 30 minutes at room temperature; for Oil Red staining only, cells were washed with distilled water and $60 \%$ isopropanol. Cells were thereafter maintained with the corresponding staining for five minutes, rinsed with distilled water three times to remove excess stain, and then photographed by using an inverted microscope (Eclipse TE300, Nikon) and a digital camera system for imaging (Digital Net Camera DN100, Nikon).

For chondrogenic differentiation, $2.5 \times 10^{5}$ cells were centrifuged $(150 \times \mathrm{g}$, five minutes $)$ at room temperature. The resulting cell pellets were cultured for 24 days in $15 \mathrm{ml}$ polystyrene centrifugation tubes in differentiation medium, with medium changed every 3 days. The resulting nodular cell clusters were embedded in paraffin (Carl Roth $\mathrm{GmbH}$, Karlsruhe, Germany) and 10$\mu \mathrm{m}$-thick sections were stained with Alcian Blue (1\% in $30 \%$ acetic acid) and Toluidine Blue $\mathrm{O}$ (both from Sigma-Aldrich) for 30 and 2 minutes, respectively, for chondrogenic extra-cellular matrix containing hyaluronic acids. Briefly, the stained preparations were washed in running water for two minutes, rinsed in distilled water, dehydrated in graded ethanol series, followed by three clarification steps in xylene and mounting. The cover-slipped slides were then photographed by using an inverted microscope (Eclipse TE300, Nikon) and a digital camera system for imaging (Digital Net Camera DN100, Nikon). The negative controls were represented by corresponding MSCs at P5 not cultured into differentiation media.

\section{Endothelial differentiation assays}

For the purpose of testing the true endothelial differentiation potential of WJ explant- and pellet-derived MSCs, isolated in a highly selective medium for MSCs, we conducted parallel endothelial differentiation assays, by using two cell groups (A and B). Cells from group A $(\mathrm{n}=5)$ were either explant- or pellet-derived MSCs isolated and expanded in the XF medium until P2, and thereafter exposed to endothelial differentiation conditions for five consecutive passages. Cells from group B $(\mathrm{n}=5)$ consisted of adherent cells resulted from either WJ-derived explants or pellets, directly cultured from P0 to P5 in endothelial differentiation conditions. The protocols applied for WJ isolation and mechanical/enzymatic dissociation, as well as for endothelial differentiation, were identical for both cell groups.
Endothelial differentiation conditions consisted of explants/cells seeding onto culture flasks pre-coated with $2 \mu \mathrm{g} / \mathrm{cm}^{2}$ fibronectin (BD Biosciences, San Jose, CA, USA), in Endothelial Cell Growth Medium MV2 (Promocell, Heidelberg, Germany), supplemented with $20 \%$ FBS and $40 \mathrm{ng} / \mathrm{ml}$ vascular endothelial growth factor (VEGF). The cells were kept in normoxic conditions in a humidified atmosphere for five serial passages. Endothelial differentiation was assessed by morphology, flow cytometry, qualitative reverse transcription (RT) polymerase chain reaction (PCR) and real-time quantitative RT-PCR (qRT-PCR), as well as Matrigel tube formation assay.

\section{Flow cytometry analysis}

Expression of cell surface molecules on WJ explant- and pellet-derived MSCs at P2 and P5 $(n=5)$ cultured in the XF medium was assessed by using a FACSCalibur instrument (BD, Franklin Lakes, NJ, USA). Surface marker expression on WJ explant- and pellet-derived cells cultured in endothelial differentiation conditions for five passages (groups $\mathrm{A}$ and $\mathrm{B}, \mathrm{n}=5$ for each group) was analyzed by using a MoFlo FACS instrument (Dako, Glostrup, Denmark). The controls were represented by enzymatically dissociated, freshly isolated WJ cells $(n=3)$ and a NUFF1 human fibroblast cell line. To this purpose, $1 \times 10^{5}$ cells were stained with fluorochromeconjugated (either phycoerythrin (PE) or fluorescein isothiocyanate (FITC)) antibodies against CD31, CD34, CD44, CD45, CD73, CD90, CD105, CD144 and CD309 (VEGF receptor (VEGFR) 2) antibodies (MACS, Miltenyi Biotec). Enzymatically-detached cells, using the MesenCult ${ }^{\mathrm{TM}}$ Dissociation Kit (STEMCELL Technologies ${ }^{\mathrm{Ta}}$ Inc.) for MSCs and accutase (Sigma-Aldrich) for cells cultured in the endothelial differentiation medium, were washed in $1 \times$ PBS containing $2 \%$ FBS and incubated for 30 minutes at $4^{\circ} \mathrm{C}$ with the appropriate diluted FITC-/PE-conjugated antibodies (1:100 dilution for CD90 antibody and 1:50 dilution for the rest of antibodies, in $1 \times$ PBS containing $2 \%$ FBS). For isotype control, the cells were stained with 1:50 diluted isotype-matched IgG (IgG1, MACS, MiltenyiBiotec). Ten thousand cells were acquired from each sample and flow cytometry data were analyzed using either the CellQuest Pro (BD) or Summit 4.0 (Dako) softwares, according to the instrument used. Median fluorescence intensity (MFI) was measured for each surface marker and background values were subtracted to obtain $\triangle$ MFI.

\section{$R T-P C R$ and $q R T-P C R$}

Molecular characterization of cells used in differentiation assays was done by RT-PCR and qRT-PCR. For qRT-PCR, total RNA was extracted with the PureLink ${ }^{\mathrm{TM}}$ 
RNA Mini Kit (Life Technologies ${ }^{\mathrm{Tm}}$, Carlsbad, CA, USA). First-strand cDNA synthesis was performed on $1 \mu \mathrm{g}$ of total RNA; cDNA samples were thereafter amplified in triplicates by using a real-time PCR system (Applied Biosystems 7900HT Fast, Life Technologies ${ }^{\mathrm{Tt}}$ ) for $40 \mathrm{cy}-$ cles $\left(95^{\circ} \mathrm{C}\right.$ for 2 minutes, $95^{\circ} \mathrm{C}$ for $5 \mathrm{sec}, 60^{\circ} \mathrm{C}$ for $10 \mathrm{sec}$, $72^{\circ} \mathrm{C}$ for $15 \mathrm{sec}$, plus a dissociation cycle at $95^{\circ} \mathrm{C}$ for 15 sec and $60^{\circ} \mathrm{C}$ for $15 \mathrm{sec}$ ) with specific oligonucleotide primers (Applied Biosystems-Life Technologies ${ }^{\mathrm{Tw}}$, Carlsbad, CA, USA) to assess quantitative mRNA expression for osteocalcin, aggrecan, CD31, von Willebrand factor (vWF) and glyceraldehyde 3-phosphate dehydrogenase (GAPDH), as endogenous control. WJ-MSCs not used into differentiation assays and enzymatically dissociated, freshly isolated WJ cells were used as controls; qRT-PCR data were analyzed by using the SDS 2.4 Standalone software (Applied Biosystems-Life Technologies $\left.{ }^{\mathrm{Tm}}\right)$. For RT-PCR, total RNA was extracted with the GenElute ${ }^{\mathrm{m}}$ Mammalian Total RNA Miniprep Kit (Sigma-Aldrich). First-strand cDNA synthesis was performed on $1 \mu \mathrm{g}$ of total RNA; cDNA samples were thereafter amplified in a thermocycler (Bio-Rad Laboratories, Hercules, CA, USA) for 35 cycles $\left(94^{\circ} \mathrm{C}\right.$ for $45 \mathrm{sec}, 60^{\circ} \mathrm{C}$ for $45 \mathrm{sec}$ and $72^{\circ} \mathrm{C}$ for $45 \mathrm{sec}$ ) with specific oligonucleotide primers (Metabion, Martinsried, Germany) to assess mRNA expression for CD31, CD34, CD144, VEGFR1, VEGFR2, vWF, GATA2, Tie-2 and GAPDH, as endogenous control. Enzymatically dissociated, freshly isolated WJ cells and a human umbilical vein endothelial cell (HUVEC) line (Promocell) were used as controls. The oligonucleotide primer sequences for both RT-PCR and qRT-PCR are shown in Table 1.

\section{Matrigel assay}

Matrigel assay was performed by using $50 \mu \mathrm{l}$ of Matrigel Basement Membrane Matrix (BD Biosciences) added to 48-well plates; the Matrigel was allowed to solidify at $37^{\circ} \mathrm{C}$ for 30 minutes and $5 \times 10^{4}$ cells were, thereafter, suspended in $100 \mu \mathrm{l}$ Endothelial Cell Growth Medium MV2 (Promocell), supplemented with 20\% FBS and 40 $\mathrm{ng} / \mathrm{ml}$ VEGF, and plated onto the Matrigel layer. A HUVEC line (Promocell) was used as a positive control. After 24 hours, the medium was removed and the formation of vascular tube-like structures was assessed with an inverted microscope (Eclipse TS100, Nikon) and a digital camera system for imaging (Digital SLR Camera D300, Nikon).

\section{Statistical analyses}

Statistical analyses were performed either by a one-way analysis of variance (ANOVA) with the Microcal OriginPro - version 6.0 software (OriginLab Corporation, Northampton, MA, USA) or by a two-tailed unpaired $t$ test with the GraphPad Prism 4 software (GraphPad
Software, Inc., La Jolla, CA, USA). The results were presented as mean \pm standard error of the mean and differences were considered statistically significant when $P$-value $<0.05$.

\section{Results}

\section{WJ mesenchymal-like cells highly proliferate in the XF} medium

In order to test whether the XF medium is suitable for WJ-MSCs isolation and expansion, we isolated WJ cells using two different approaches, either from WJ explants or enzymatically dissociated WJ cells. Our results demonstrated that primary cultures of adherent cells, with a mesenchymal-like morphology, grew in colonies out of the WJ explants (Figure 2.A.1a, 1b) and were subcultured, on average, at 14 days after plating, whereas adherent cells resulting from culture of suspended WJ-derived pellets (Figure 2.A.2a, 2b) reached $80 \%$ confluence and were subcultured, on average, at 10 days after plating. Both explant and pellet-derived cells maintained their morphology after subsequent subculturing (Figure 2.B.3a, 3b and 4a, $4 \mathrm{~b}$, respectively). Furthermore, both cell population types presented a high proliferation rate, which doubled every 24 hours $(P<0.05)$ during the first week of assessment (Figure 2.C). Thus, the XF medium was suitable for the isolation of both WJ explant- and pellet-derived adherent cells with a mesenchymal-like phenotype and a high proliferation rate.

\section{WJ-derived cells cultured in the XF medium presented MSC characteristics}

For the purpose of testing if the XF medium could lead to the isolation and expansion of cells with true MSC characteristics, we assessed their functional ability to differentiate into adipogenic, osteogenic and chondrogenic lineages, as well as the presence of MSC molecules at gene and protein levels. The cyto/histochemical staining of in vitro differentiation assay preparations revealed that, under specific culture conditions, both WJ explantand pellet-derived MSCs, isolated and expanded in the XF medium, presented adipogenic, osteogenic and chondrogenic differentiation capacity (Figure 3.I.A, I.B), as compared to controls represented by WJ explant (data not shown) and pellet-derived MSCs (Figure 3.I.C) not cultured in differentiation media that did not show three-lineage differentiation potential. In respect to the degree of adipogenic differentiation, accumulation of lipid droplets was more robust in WJ pellet-derived MSCs at P5, as compared to WJ pellet-derived MSCs at P2 and WJ explant-derived MSCs (Figure 3.II.A, II.B).

Furthermore, quantitative gene expression of osteocalcin and aggrecan, involved in MSCs differentiation into osteogenic and chondrogenic lineages, respectively, significantly increased $(P<0.05)$ in explant-derived MSCs, as compared 
Table 1 Sequences of the oligonucleotide primers used for qRT-PCR and RT-PCR

\begin{tabular}{|c|c|c|c|}
\hline Gene & GeneBank $^{\circledR}$ accession number & Sequences of oligonucleotide primers & Predicted size (bp) \\
\hline \multicolumn{4}{|l|}{ qRT-PCR } \\
\hline \multirow[t]{2}{*}{$V V F$} & [NM_000552.3] & S: 5'-CGACATGGAGGATGCCGT-3' & 236 \\
\hline & & A: 5'-ACTCATTGATGAGGCAGGGGT-3' & \\
\hline \multirow[t]{2}{*}{ CD31 } & [NM_000442.4] & S: 5'-CTGCTGACCCTTCTGCTCTG-3' & 203 \\
\hline & & A: 5'-TAAAACAGCACGTCATCCTTATAGA-3' & \\
\hline \multirow[t]{2}{*}{ GAPDH } & [NM_002046] & S: 5'-TTGGTATCGTGGAAGGACTCA-3' & 270 \\
\hline & & A: 5'-TGTCATCATATTTGGCAGGTTI-3' & \\
\hline \multirow[t]{2}{*}{ Aggrecan } & [NM_001135.3] & S: 5'-GTGCCTATCAGGACAAGGTCT-3' & 167 \\
\hline & & A: 5'-GATGCCTTTCACCACGACTTC-3 & \\
\hline \multirow[t]{2}{*}{ Osteocalcin } & [NM_199173.4] & S: 5'-GCCCTCACACTCCTCGCCCTA-3' & 100 \\
\hline & & A: 5'-AGGCTGCACCTTTGCTGGACTC-3 & \\
\hline \multirow[t]{2}{*}{ GAPDH } & [NM_001256799.1] & S: 5'-TTGGTATCGTGGAAGGACTCA-3' & 267 \\
\hline & & A: 5'-TGTCATATTTGGCAGGTTT-3 & \\
\hline \multicolumn{4}{|l|}{ RT-PCR } \\
\hline \multirow[t]{2}{*}{ CD31 } & [NM_000442] & S: 5'-AGCACCACCTCTCACGTCA-3' & 250 \\
\hline & & A: 5'-CTTGGATGGCCTCTITCTTG-3' & \\
\hline \multirow[t]{2}{*}{ CD144 } & [NM_001795] & S: 5'-CCTTGGGATAGCAAACTCCA-3' & 283 \\
\hline & & A: 5'-CTTGCCTCCAGGCAGATAG-3' & \\
\hline \multirow[t]{2}{*}{ CD34 } & [NM_001773] & S: 5'-TCAGTTCTAGTCTCTCTGGGGC-3' & 328 \\
\hline & & A: 5'-ATAAGGGTTAGGAGCTGATCTGG-3' & \\
\hline \multirow[t]{2}{*}{ VEGFR1 } & [NM_002019] & S: 5'-CAGCCCATAAATGGTCTTTGCC-3' & 557 \\
\hline & & A: 5'-TAATTTGACTGGGCGTGGTGTG-3' & \\
\hline \multirow[t]{2}{*}{ VEGFR2 } & [NM_002253] & S: 5'-GTGACCAACATGGAGTCGTG-3' & 660 \\
\hline & & A: 5'-CCAGAGATTCCATGCCACTT-3' & \\
\hline \multirow[t]{2}{*}{ VWF } & [NM_000552] & S: 5'-CGACTTCCTTACCCCCTCTG-3' & 247 \\
\hline & & A: 5'-GCAGGAGCACACGTCGTAG-3' & \\
\hline \multirow[t]{2}{*}{ GATA2 } & [NM_032638] & S: 5'-CCCTAAGCAGCGCAGCAAGAC-3' & 439 \\
\hline & & A: 5'-TGACTTCTCCTGCATGCACT-3' & \\
\hline \multirow[t]{2}{*}{ Tie-2 } & [NM_000459] & S: 5'-CATACTGGGGAAAGCAATGAAAC-3' & 281 \\
\hline & & A: 5'-ACCACTGTITTCACCTTCCAAA-3' & \\
\hline \multirow[t]{2}{*}{ GAPDH } & [NM_002046] & S: 5'-ACCACAGTCCATGCCATCAC-3' & 450 \\
\hline & & A: 5'-TCCACCACCCTGTTGCTGTA-3' & \\
\hline
\end{tabular}

A, antisense; S, sense.

to controls and by passage progression. Interestingly, in pellet-derived MSCs, both aggrecan and osteocalcin gene expression were significantly increased $(P<0.05)$ at $\mathrm{P} 2$ as compared to controls, but significantly decreased $(P<$ 0.05 ) by passage progression (Figure $4.1 \mathrm{a}, 1 \mathrm{~b}$ ).

In addition, flow cytometry analysis of XF medium cultured MSCs, derived from both WJ explants and cell pellets, revealed that the cells were positive, at both P2 (Figure 5.1 and 2, respectively) and P5 (data not shown) for MSC surface markers such as CD44, CD73, CD90 and CD105, and were negative for hematopoietic stem cell (CD34) and monocyte-macrophage (CD45) markers; interestingly, enzymatically dissociated, freshly isolated WJ cells (P0) showed only CD44 surface marker expression (Figure 6.C). When we compared MFI of MSC markers between passages, the WJ explant-derived MSCs had a statistical significantly higher $(P<0.05)$ CD73 expression at P5, as compared to P2 (Figure 5.3a). Furthermore, MSCs derived from WJ cell pellets exhibited a statistical significantly higher $(P<0.05)$ expression of CD44 at P2, as compared to P0 and P5, and a statistical significantly higher $(P<0.05)$ expression of CD73 marker at P2, as compared to P5 (Figure 5.3b). Moreover, when we compared explant- versus pellet- 

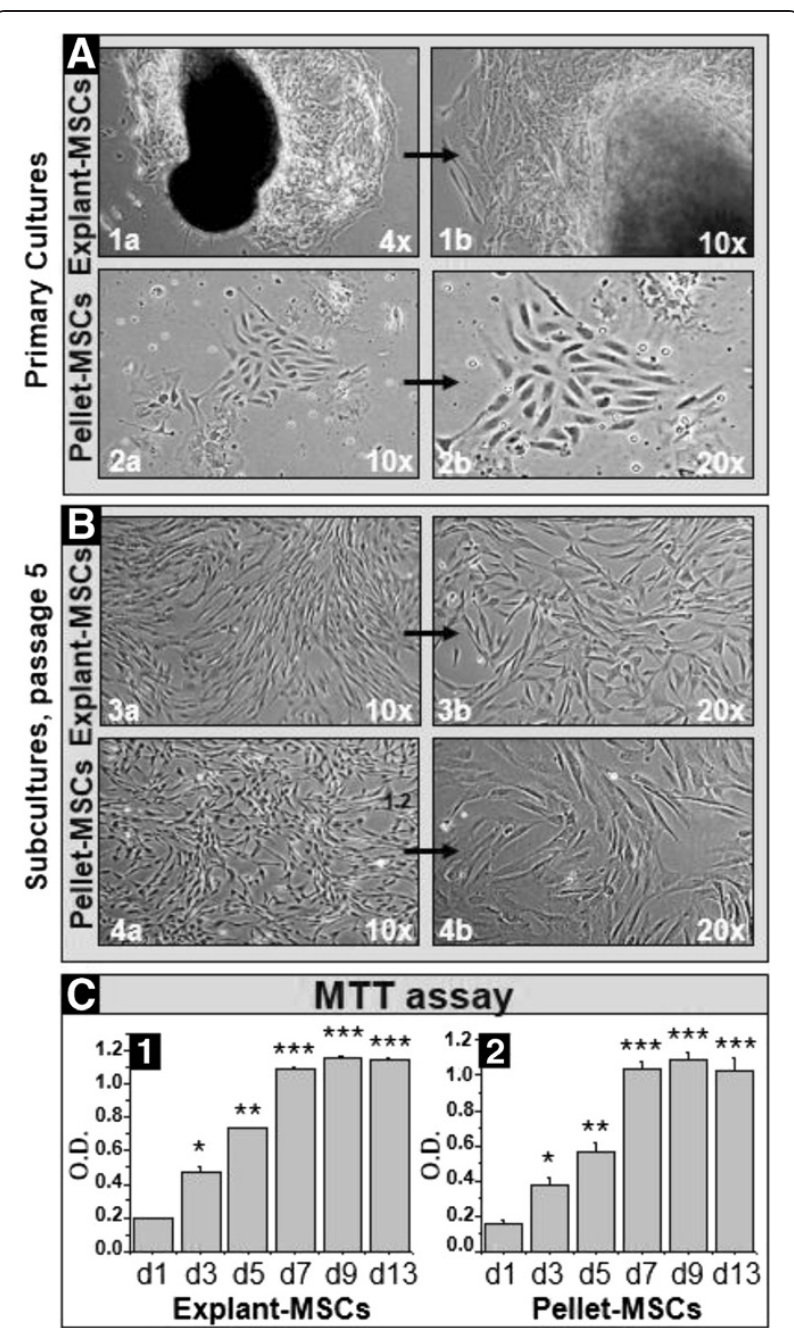

Figure 2 Assessment of morphology and proliferation rate of MSCs isolated and subcultured in XF medium. A. Morphological evaluation of primary MSC cultures derived from WJ explants (explantMSCs -1a, 1b) and enzymatically dissociated WJ (pellet-MSCs - 2a, 2 $\mathbf{b}$ ); B. Morphological evaluation of P5 subcultures of WJ explant (3a, 3b)- and pellet (4a, $\mathbf{4 b}$ )-derived MSCs; higher magnifications of corresponding pictures are pointed by arrows; C. MTT assay on WJ explant (1)- and pellet (2)-derived MSCs at P2; d, day of assessment; ${ }^{*},{ }^{* *},{ }^{* * *}, P<0.05$, indicates statistical significance in cell proliferation during consecutive time points of assessment (*, Day 3 vs. Day 1; **, Day 5 vs. Day 3; *** days 7, 9, 13 vs. Day 5). MSCs, mesenchymal stem cells; $P$, passage; $W J$, Wharton's jelly; $X F$, xeno-free.

derived MSCs, pellet-derived cells at P2 expressed a statistical significantly higher MFI for CD44 and CD73 markers $(P<0.005$ and $P<0.05$, respectively) than the explant-derived counterparts and a statistical significantly higher MFI $(P<0.005)$ for CD44 marker, as opposed to pellet-derived WJ cells at P0 (Figure 5.3c). Taken together, the results of in vitro differentiation assays corroborated with the results of MSC molecules assessment indicated that both WJ explant- and pellet-derived adherent cells cultured in the XF medium showed different degrees of multipotent differentiation and expression of markers characteristic for MSCs, according to the isolation method and/or passage number.

\section{WJ-MSCs cultured in the XF medium did not subsequently differentiate into endothelial cells}

In order to investigate if the WJ-MSCs isolated and expanded in the XF medium could differentiate into endothelial cells, we performed endothelial differentiation assays. Upon exposure for five serial passages to endothelial differentiation medium, both WJ explantand cell pellet-derived MSCs isolated and expanded until P2 in the XF medium (group A), presented a fibroblastlike morphology (Figure 7.I.A.1a/1b and $3 \mathrm{a} / 3 \mathrm{~b}$, respectively) and did not form tube-like structures upon culture on Matrigel basement membrane matrix (Figure 7.II.A.1 and 4, respectively). By contrast, adherent cells from group $\mathrm{B}$, isolated and subcultured for five consecutive passages in endothelial differentiation conditions, derived from WJ cell pellets, developed an epithelial-like morphology and presented functional characteristics of endothelial cells by forming vascular tube-like structures in Matrigel (Figure 7.I.B.4a/4b and II.B.5a/5b, respectively), while the WJ explant-derived counterparts maintained a fibroblast-like morphology and did not exhibit tube-forming characteristics (Figure 7.I.B.2a/2b and II.B.2, respectively).

Furthermore, flow cytometry analyses indicated that both explant- and pellet-derived cells belonging to group A did not express endothelial surface molecules and maintained the expression of CD44, CD73 and CD90 MSC markers, while losing CD105 marker expression (Figure 6.A.1 and A.2, respectively); however, WJ pelletderived cells showed a statistical significantly higher $(P<0.05)$ CD44 expression than freshly isolated WJderived cells (P0) and a statistical significantly higher $(P<0.05)$ CD73 expression, as compared to explantderived cells (Figure 6.D.a). Within group B, explantderived cells also did not show endothelial surface molecules, but expressed CD44, CD73 and CD90 MSC markers (Figure 6.B.1). Interestingly, the pellet-derived cells belonging to group $\mathrm{B}$ presented a high expression of CD44 and CD73, but not CD90 markers; furthermore, they presented an endothelial phenotype through expression of CD31, CD105 and CD144 surface molecules (Figure 6.B.2). When we compared MSC markers expression between groups $\mathrm{A}$ and $\mathrm{B}$, the only statistically significant differences applied to explant-derived cells, whose CD44 and CD90 expression was higher $(P<0.05$ and $P=0.0005$, respectively) in group $\mathrm{B}$, as compared to group A cells (Figure 6.D.b).

Moreover, quantitative gene expression of $\nu W F$ and CD31 endothelial markers did not significantly increase in group A cells, as compared to controls (Figure 4.2a 


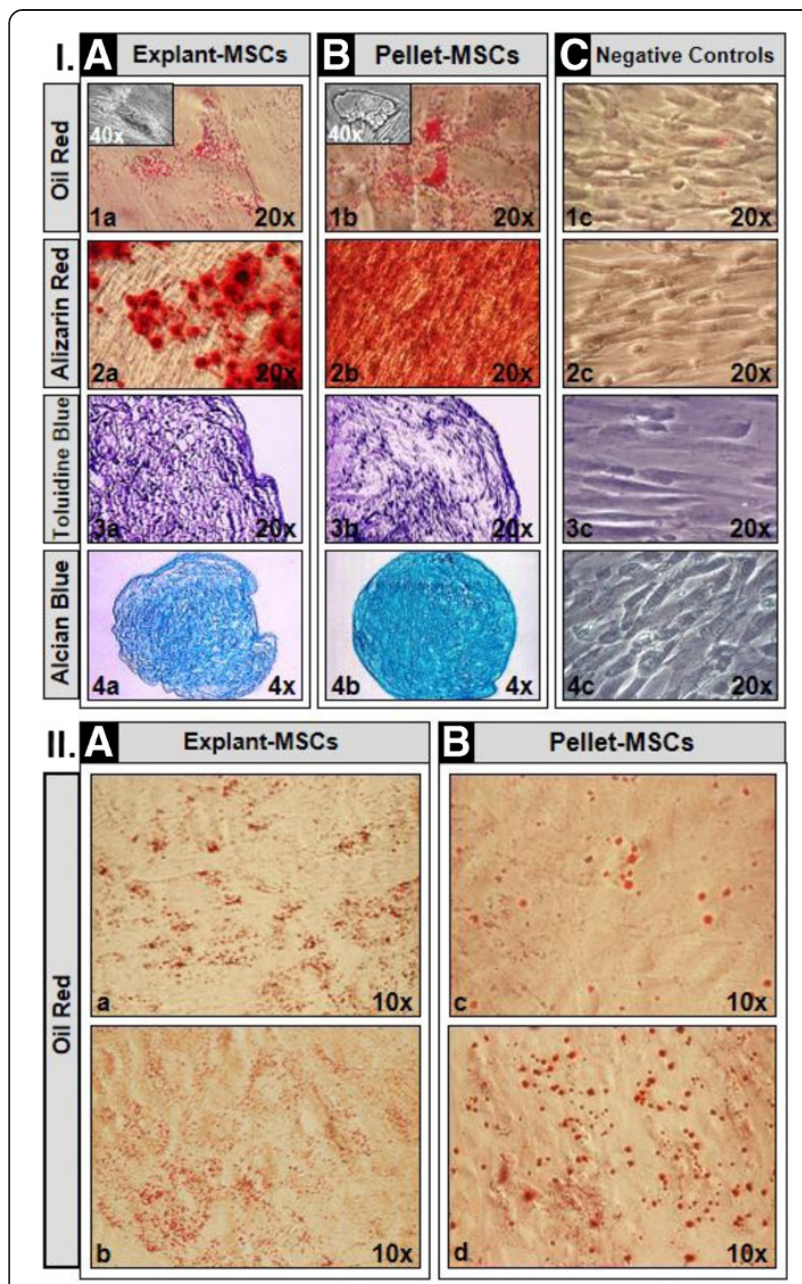

Figure 3 In vitro differentiation assays of WJ-MSCs at P2/P5, isolated and expanded in XF medium. I. Representative images of MSCs, isolated from both WJ explants (explant-MSCs, A) and enzymatically dissociated WJ (pellet-MSCS, B), showing differentiation towards the adipocyte (A.1a - P5, B.1b - P2), osteocyte (A.2a - P5, B.2b - P2) and chondrocyte (A.3a/4a - P5, B.3b/4b - P2) lineages, as assessed by Oil Red, Alizarin Red and Toluidine Blue/ Alcian Blue staining, respectively; C. Negative controls, represented by corresponding pellet-derived MSCs not used in differentiation assays and stained with Oil Red (C.1C), Alizarin Red (C.2C), Toluidine blue (C.3C) and Alcian Blue (C.4C); II.A and B. Representative, lower magnification (10x) images of adipogenic differentiation of WJ explant (a - P2; b - P5)- and pellet (C - P2; d - P5)-derived MSCS. MSCs, mesenchymal stem cells; $P$, passage; WJ, Wharton's jelly; XF, xeno-free.

and $2 \mathrm{~b}$, respectively). By contrast, pellet-derived cells belonging to group $B$ had an increased quantitative mRNA expression for $v W F$ and $C D 31$ markers (Figure 4.2c and $2 \mathrm{~d}$, respectively), as compared to enzymatically dissociated, freshly isolated WJ cells $(P<0.05)$ and cells from group $\mathrm{A}$ at a corresponding passage. The gene profile of cells belonging to groups A and B was further documented by RT-PCR, showing that only enzymatically dissociated, freshly isolated WJ cells (P0) and pellet- derived cells belonging to group B expressed CD31, CD144 and $v W F$ markers involved in endothelial cells differentiation, proliferation and survival, as well as GATA2 transcription factor that promotes angiogenesis [40]; VEGFR1, with a role in stem cell recruitment [41], chemokine receptors VEGFR2 and/or Tie-2, important in stem/progenitor cells homing were also shared by cells belonging to group A and Explant-derived cells belonging to group B (Figure 4.3).

Overall, the results of endothelial differentiation assays indicated that the endothelial differentiation capacity of WJ-derived adherent cells depended on the cell isolation method and initial culture conditions.

\section{Discussion}

In this study, we report that the use of a selective, XF culture medium, specifically designed for MSCs, led to the isolation from human WJ explants and enzymatically dissociated WJ of cell populations with MSC characteristics as assessed at gene, protein and functional levels, which were differently expressed according to the cell isolation method used. Furthermore, we demonstrated that the initial culture conditions, used for the isolation and expansion of WJ-MSCs, resulted in lack of subsequent endothelial differentiation potential. Therefore, the use of defined MSC culture media is a prerequisite for the establishment of the real capacity of WJ-MSCs to differentiate towards the endothelial lineage.

The WJ-derived cells isolated and expanded in a MSC XF medium proved to present a robust MSC profile through expression of CD44/CD73/CD90/CD105 surface markers, multipotent differentiation potential into adipogenic, osteogenic and chondrogenic cell lineages, as well as a high proliferation rate. When BM-MSCs $[26,42,43]$, which expressed less growth-related genes as compared to WJ-MSCs [44], and adipose stem cells [25] were manipulated in vitro by using XF media, they proliferated more rapidly than the cells cultured by using conventional media. In addition, MSCs derived from enzymatically-digested whole human umbilical cord segments [45] and umbilical cord matrix [46] had a higher expansion potential when cultured in serum-free/XF media, as compared to FBS-based media cultured counterparts and BM-MSCs/adipose stem cells, respectively. Although we did not compare in this study XF versus conventional culture media, our results corroborated with the literature data further indicate that the XF conditions described here might bring an advantage over the conventional media, in respect of proliferation properties of WJ-MSCs.

We also demonstrated significant differences in CD44, CD73 and CD90 surface marker expression in WJ-MSCs cultured in XF conditions, as well as in WJ-MSCs and WJ-derived adherent cells exposed to endothelial 

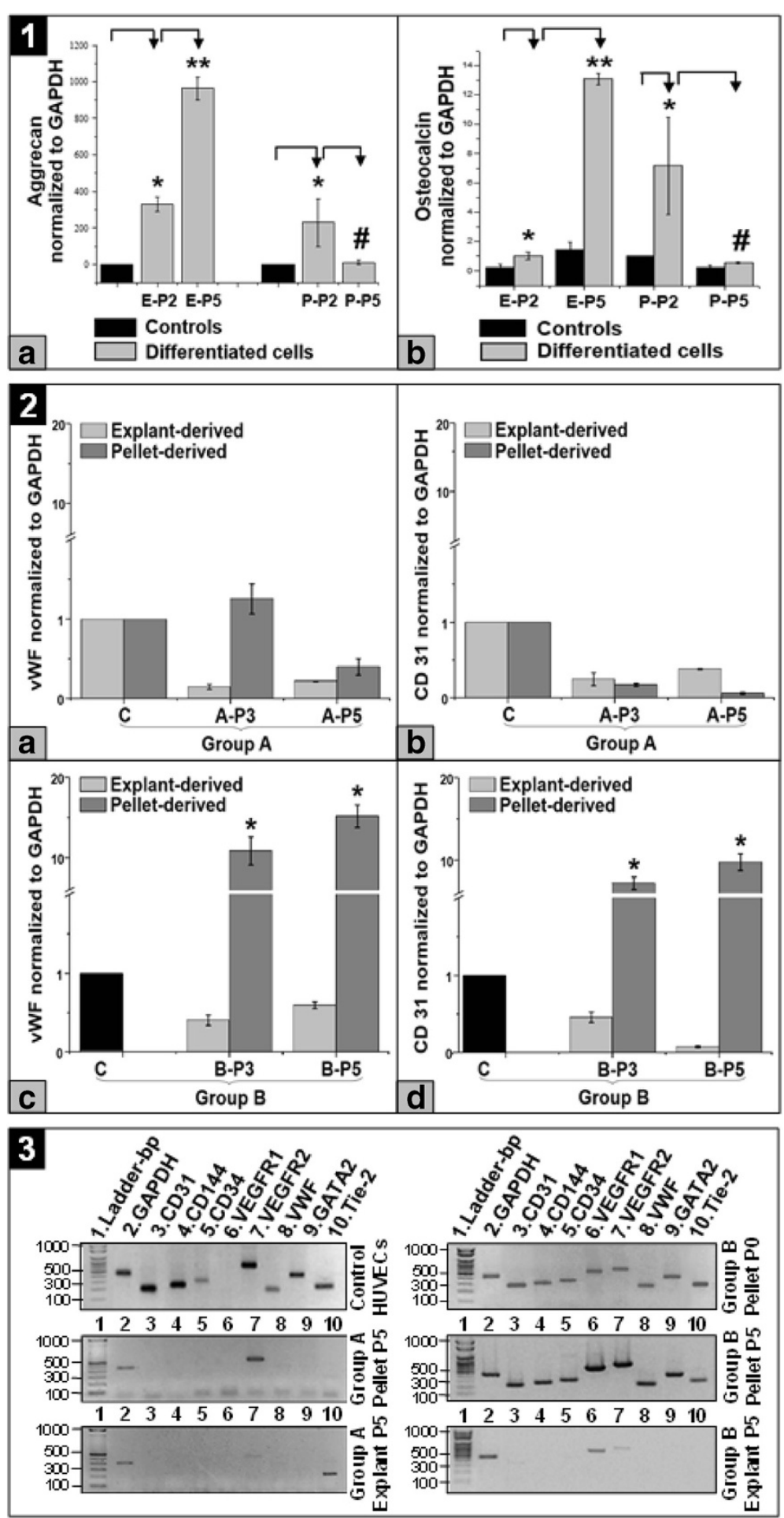

Figure 4 (See legend on next page.) 
(See figure on previous page.)

Figure 4 Gene expression profiles in WJ-derived cells. 1. Aggrecan (a) and osteocalcin (b) quantitative gene expression profiles at P2 and P5 in WJ explant (E-P2, E-P5)- and pellet (P-P2, P-P5)-derived MSCs isolated and expanded in the XF medium, as compared to controls represented by WJ-MSCs at P5 (a) and P2/P5 (b), not employed into differentiation assays; ${ }^{*}$ and ${ }^{* *}$, statistically significant increase in gene expression $(P<0.05)$, as compared to control and previous passage, respectively; \#, statistically significant decrease in gene expression $(P<0.05)$, as compared to previous passage; 2 . Quantitative $v W F$ (a) and CD31 (b) gene expression profiles in explant- and pellet-derived cells belonging to group A at P3 and P5 (A-P3, A-P5, C = Controls represented by explant- and pellet-derived WJ-MSCs not used into endothelial differentiation assay); Quantitative $V W F$ (c) and CD31 (d) gene expression profiles in explant- and pelletderived cells belonging to group B at P3 and P5 (B-P3, B-P5, C = Control represented by enzymatically dissociated, freshly isolated WJ cells, ${ }^{*}=$ statistically significant increase in gene expression ( $P<0.05$ ) between group B Control (C) and B-P3/B-P5); 3. Qualitative endothelial gene expression profiles in WJ explantand pellet-derived cells belonging to groups A and B, after five passages of exposure to endothelial medium, as compared to enzymatically dissociated, freshly isolated WJ cells (pellet-P0) and HUVECs. HUVECs, human umbilical vein endothelial cells; MSCs, mesenchymal stem cells; P, passage; vWF, von Willebrand factor; WJ, Wharton's jelly; XF, xeno-free.

differentiation conditions, depending on the cell isolation method used or the passage number. It is well known that both in vitro cell manipulation technique [47] and passage number [48] exert a prominent impact on the protein expression profile of MSCs. The issue of heterogeneity in MSC markers expression has also been reported for BM-MSCs and has been correlated with their proliferation and differentiation potential [49]. It has been shown that CD44, CD73 and CD90 markers were expressed at higher levels in umbilical cord-derived MSC subpopulations that exhibited a higher proliferation capacity and a reduced amount of aging cells [50]. In addition, CD44, a cell-surface receptor for hyaluronic acid, facilitated MSCs migration through interaction with extracellular hyaluronic acid, suggesting that such migratory mechanism could be critical for MSCs recruitment to tissue regeneration sites [51]. As CD44 and CD90 are involved in cell-to-cell interactions, cell adhesion and migration, and CD73 plays an important role in cell cycle progression and apoptosis, they might differently control these processes in WJ explant- versus pellet-derived cells, nevertheless by passage propagation. Therefore, the biological benefits of such heterogeneity in the level of surface markers' expression may be related to the proposed functions of these cells. Further insights into these markers' expression by WJ-MSCs manipulated in XF culture conditions are worthwhile in order to modulate biological processes, such as cell adhesion, migration and proliferation, to optimize clinical cell therapy approaches. Thus, the development of

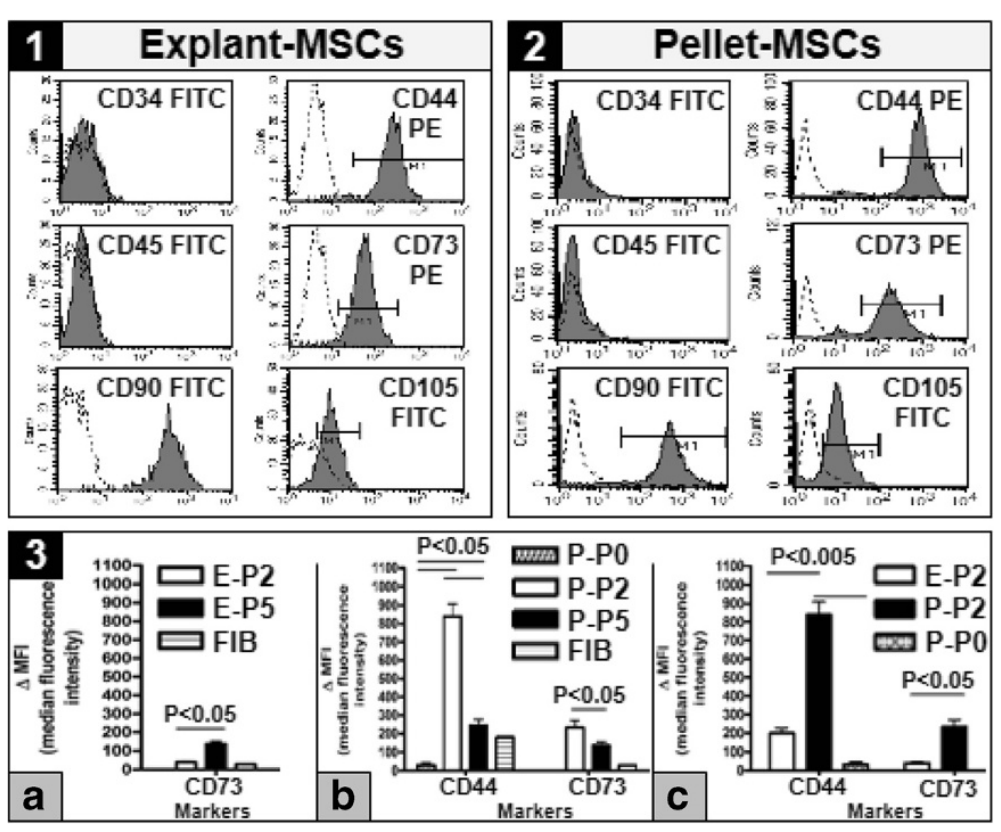

Figure 5 Flow cytometry analysis of WJ explant- and pellet-derived MSCs cultured in XF medium. MSC markers expression by WJ explant (1)- and pellet (2)-derived MSCs at P2; (3) Comparative MFI expression of CD44 and/or CD73 markers in: (3a) Explant-derived MSCs at P2 (E-P2) versus P5 (E-P5); (3b) Pellet-derived MSCs at P2 (P-P2) versus P5 (P-P5), as compared to freshly isolated pellet-derived WJ cells (P-P0) and a commercially available NUFF1 human fibroblast cell line (FIB); (3c) explant-derived MSCs at P2 (E-P2) versus pellet-derived MSCS at P2 (P-P2), as compared to freshly isolated pellet-derived WJ cells (P-P0). MFI, median fluorescence intensity; MSCs, mesenchymal stem cells; P, passage; WJ, Wharton's jelly; XF, xeno-free. 

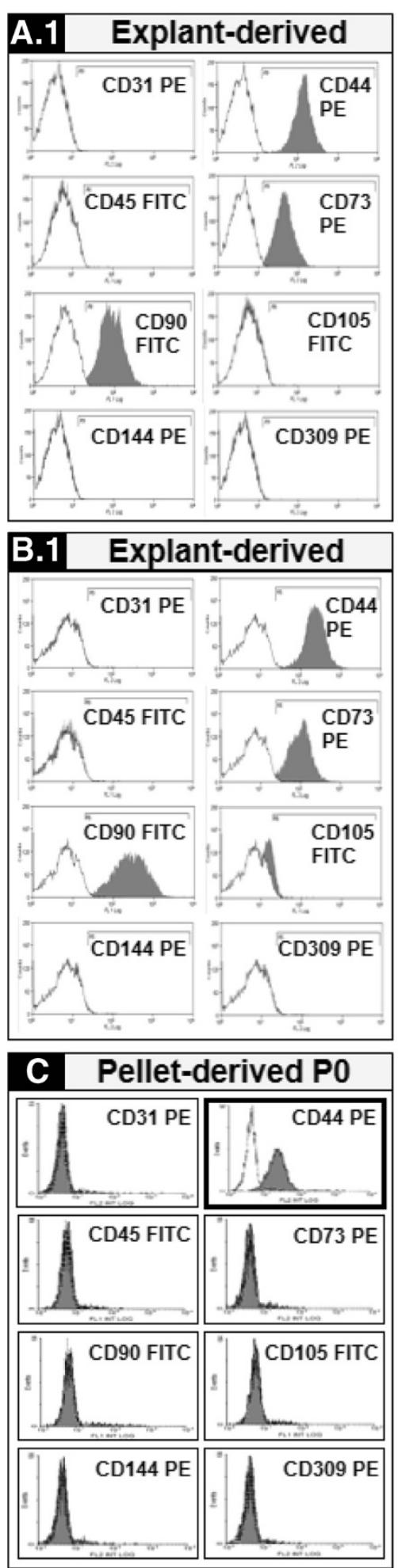
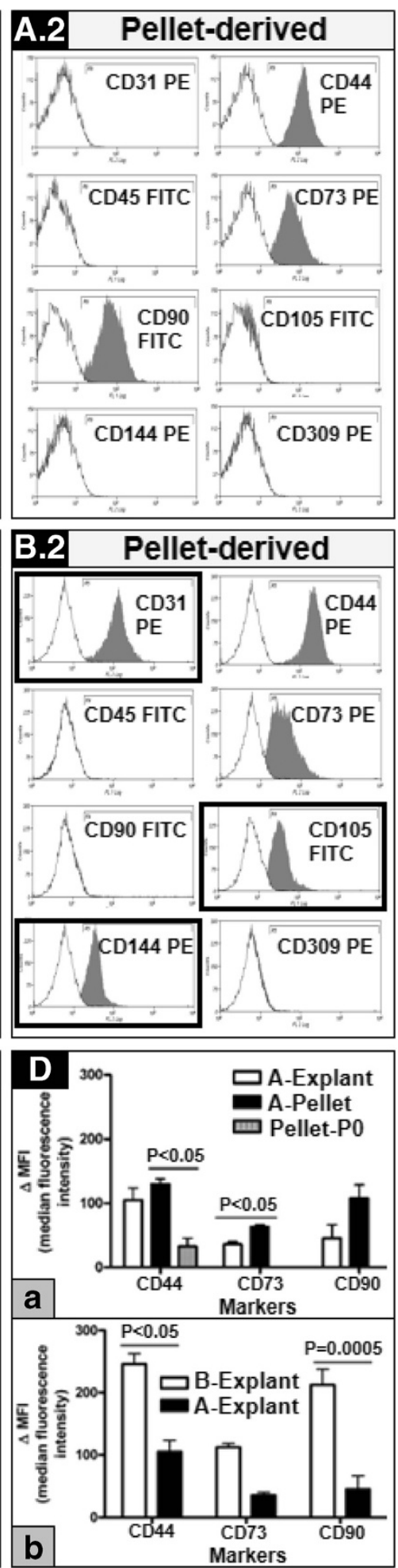
(See figure on previous page.)

Figure 6 Flow cytometry analysis of WJ-derived cells cultured in endothelial medium after isolation/expansion in different conditions. A.1 and A.2 - explant- and pellet-derived cells, respectively, belonging to group A, isolated and expanded until P2 in the XF medium, and then subcultured for five consecutive passages in endothelial medium, showed lack of endothelial surface markers;

B.1 and B.2 - explant- and pellet-derived cells, respectively belonging to group B, isolated and subcultured for five consecutive passages in endothelial medium, showed differential expression of surface markers: explant-derived cells (B.1) did not gain endothelial surface markers expression, whereas pellet-derived cells (B.2) exhibited CD31, CD105 and CD144 surface markers expression upon culture into the endothelial medium; C. Surface markers expression on enzymatically dissociated, freshly isolated WJ cells (pellet-derived P0); D. Comparative MFI expression of CD44, CD73 and CD90 markers, upon exposure to endothelial differentiation conditions, in: (D.a) explant- versus pellet-derived cells belonging to group A (A), as compared to enzymatically dissociated, freshly isolated WJ cells (pellet-P0); (D.b) explant-derived cells from group B (B) versus explant-derived cells from group A (A). MFI, median fluorescence intensity; P, passage; WJ, Wharton's jelly; XF, xeno-free.

protocols for isolation of distinct MSC subpopulations, based also on the expression levels of their surface markers, may provide improved vectors for the treatment of specific diseases [52].

When assessing multipotent differentiation outcomes, we demonstrated that in WJ explant- and pellet-derived MSCs, the chondrogenic and osteogenic differentiation potential increased and decreased, respectively, by passage progression. This could be due to the fact that the MSCs isolation method used (via WJ explants versus enzymatic dissociation of WJ) led to the generation of different MSC populations in respect of their multipotent differentiation capacity. It has also been documented that the passage number has an important impact on the differentiation capacity of MSCs $[48,53,54]$ due to a consistent pattern of changes in the global gene expression signature of MSCs at different passages [48]. In this respect, MSCs derived from other sources than WJ, either exhibited a decreased osteogenic differentiation capacity by passage progression [54] or calcium deposition transiently decreased from P4 to P6, but returned to levels near or above those of primary cells by P10 [55]. Therefore, further work is needed in order to elucidate the optimum isolation protocol and passage number of WJ-MSCs, grown in defined, XF conditions, to optimize their multipotent differentiation potential according to the clinical cell therapy foreseen.

Although it has been shown that WJ-MSCs cultured in conventional media presented a lower adipogenic differentiation potential as compared to other MSC sources, such as the BM [44], periodontal ligament [56] and chorionic-plate [57], we found that WJ-MSCs isolated and expanded in the XF medium presented different degrees of adipogenic differentiation, according to the isolation method and passage number; interestingly, the adipogenic differentiation capacity of WJ pelletderived MSCs was higher at P5 as compared to P2 and was inverse proportional with the osteogenic differentiation potential of these cells. This may be due to the involvement of MicroRNA-22 that was found to regulate adipogenic and osteogenic differentiation of human adipose tissue-derived MSCs in opposite directions [58], a finding that deserves to be further investigated in WJMSCs, too.

While it has been reported that both the osteogenic gene expression pattern [44] and osteogenic differentiation rate [59] were lower in WJ-MSCs as compared to BM-MSCs, isolated by using conventional media, we demonstrated a very robust osteogenic differentiation potential of WJ explant-derived MSCs, which increased by passage progression. Furthermore, the influence of the culture conditions used for MSCs isolation and expansion on gene and protein expression profile of BMMSCs [47], as well as on their osteoblastic differentiation has been demonstrated. In this regard, XF conditions used for BM-MSCs culture, through FBS substitution for allogeneic human platelet lysate, enhanced their osteogenic differentiation [43]. Hence, the WJ-MSCs isolated and expanded by using the selective, XF conditions described here might be better cell candidates for bone regeneration, as compared to WJ-MSCs manipulated in conventional media, suggesting potential superior in vivo osteogenic regeneration outcomes. In respect of the impact of the XF conditions on chondrogenic differentiation potential, it has been shown that BMMSCs that were isolated, stored and expanded using XF materials, including the XF medium used in our study, had a higher gene expression of aggrecan than cells cultured in conventional media [42]. These observations indicate that WJ-MSCs, manipulated in vitro by using XF media, might also represent superior cell candidates for cartilage repair.

Upon exposure to endothelial differentiation signals, we showed that both WJ explant- and pellet-derived cells from Group A - isolated and expanded until P2 in MSC XF medium, and then subcultured for five passages in endothelial differentiation conditions - did not exhibit endothelial differentiation potential. By contrast, pellet- but not explant-derived cells belonging to Group $\mathrm{B}$ - isolated and expanded in endothelial differentiation conditions from P0 to P5 - presented endothelial cell characteristics, being different in respect to surface and gene marker expression, as well as functional properties. This might be due to the fact that the enzymatically 


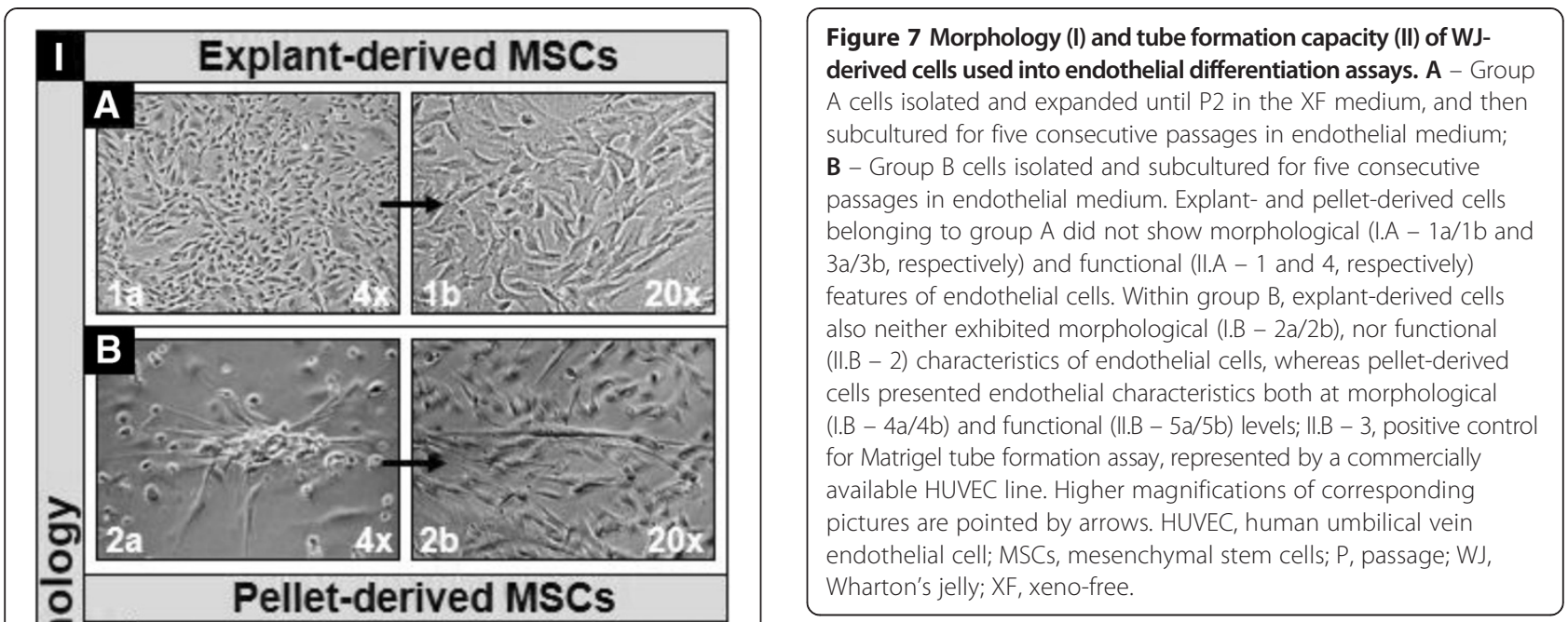

dissociated, freshly isolated WJ cell populations contained stem/progenitor cells or other contaminating endothelial cell types able to give rise to an endothelial progeny, when seeded directly into endothelium medium for five passages; in the case of explant-derived cells of group B, these cells may not migrate out of the explants. Furthermore, they may be lost when initially cultured in XF conditions.

Interestingly, we also demonstrated that, besides the endothelial markers expression at gene and protein levels, the WJ pellet-derived cells belonging to group B presented CD73 and CD44 MSC surface markers. Although there are no data yet documenting CD44 marker expression on endothelial cell outgrowth derived from WJ, it has been reported the involvement of CD44 molecule in endothelial cell proliferation, migration and angiogenesis [60], contributing to the organization and/ or stability of developing endothelial tubular networks [61]. While there is also no evidence of CD73 expression on endothelial progenitors derived from any adult tissues, Choi KD et al. [62] identified a novel population of $\mathrm{CD} 73+$ endothelial progenitors derived from human embryonic stem cells. These data and the fact that the umbilical cord is closer in development to embryonic than adult tissues [44,57], reinforce the speculation that the isolated endothelial progeny within pellet-derived cells belonging to group B resulted from a different stem/progenitor cell type than MSCs, residing in the matrix of the umbilical cord, whose isolation might have been facilitated by the use of enzymatic dissociation and initial endothelial culture conditions.

Although some reports have demonstrated endothelial differentiation of WJ-derived cells in vitro or in vivo [13,16-19], endothelial differentiation of WJ-MSCs is still very controversial. Furthermore, it has been shown that 
MSCs derived from other tissues than WJ, such as BM and adipose tissue, did not display functional properties of endothelial cells, but promoted neovascularization via paracrine mechanisms [63,64]. Choi $\mathrm{M}$ et al. [65] also demonstrated the lack of endothelial differentiation capacity of WJ-MSCs, isolated and expanded in a conventional FBS-based medium, but paying careful attention to the removal of the umbilical cord blood vessels and amnion. Upon exposure to endothelial differentiation media, these WJ-MSCs neither expressed endothelial markers, nor directly participated to angiogenesis/ vasculogenesis in vitro and in vivo; rather, the cells improved perfusion recovery and neovascularization by secreting paracrine factors and by functioning as perivascular precursor cells [65]. Our data, corroborated to this report, suggest that the MSCs' isolation method has a tremendous impact on the homogeneity of the cells and their true endothelial differentiation capacity. By contrast with other authors that did not use a selective MSC medium for WJ-MSCs isolation prior to their exposure to endothelial differentiation conditions [65] or cultured freshly isolated cells directly in endothelial differentiation media [17], we further documented, by using a defined, XF medium for MSCs, that the initial culture conditions have a strong impact on the progeny outgrowth resulted upon exposure of WJ-MSCs to endothelial differentiation signals. Based on our observations, we speculate that in the case of previous reports, describing WJ-MSCs differentiation into endothelial phenotypes, the endothelial outgrowth was derived from other types of stem cells than WJ-MSCs, circulating endothelial progenitors, or umbilical vein endothelial cells, contaminating the primary cultures during the dissection process, performed to remove the umbilical cord arteries and the vein.

It is well known that gene expression profiling is significantly different among MSCs from distinct sources and that intrinsic gene expression has an important impact on MSCs overall differentiation potential [66]. It has been postulated that BM-MSCs constitutively expressed genes related to immunomodulation, adipose tissue derived-MSCs highly expressed genes implicated in tissue development [14], whereas the transcriptome profiling of WJ-MSCs revealed an increased expression of genes involved in liver development [66] and an inherent bias towards the neuro-ectoderm lineage $[14,67]$. These observations suggest that WJ-MSCs might be better cell candidates for differentiation into hepatocyte and neuronal rather than endothelial phenotypes. As MSCs from different sources exhibit distinct and unique gene expression signatures, which make them competent to give rise to specific lineages rather than others [14], at this moment there are no well-defined master MSCs that are suitable for vascular regeneration. Therefore, according to the isolation and culture methods used, MSCs should be rigorously characterized, especially at the gene and functional levels, and much caution needs to be given when choosing the best MSC type for a particular therapeutic application.

\section{Conclusions}

Taken together, our data indicate that the isolation method and XF culture conditions influence the multipotent differentiation capacity of human WJ-MSCs. The use of a selective, XF medium for MSCs led to the isolation and expansion of MSC populations from the matrix of the umbilical cord, free of contamination with other stem, progenitor or adult cell types that may be misleading concerning the real endothelial differentiation potential of WJ-MSCs. Therefore, the availability of optimized in vitro assays, involving ready-to-use XF media for human WJ-MSCs manipulation, might have a substantial scientific and clinical potential. Thus, a priority in the field should be the standardization of isolation and culture expansion techniques in defined, XF media for an accurate characterization of WJ-MSCs, as candidates for clinical cell therapy applications.

\section{Abbreviations}

BM: Bone marrow; BM-MSCs: Bone marrow-derived mesenchymal stem cells; FBS: Fetal bovine serum; FITC: Fluorescein isothiocyanate;

GAPDH: Glyceraldehyde 3-phosphate dehydrogenase; HUVECs: Human umbilical vein endothelial cells; MFI: Median fluorescence intensity; MSCs: Mesenchymal stem cells; MTT: 3-(4,5-dimethylthiazol-2-yl)-2,5diphenyltetrazolium bromide; P: Passage; PBS: Phosphate-buffered saline; PCR: Polymerase chain reaction; PE: Phycoerythrin; QRT-PCR: Real-time quantitative reverse transcription polymerase chain reaction; RT: Reverse transcription; RT-PCR: Reverse transcription polymerase chain reaction; VEGF: Vascular endothelial growth factor; VEGFR: Vascular endothelial growth factor receptor; VWF: von Willebrand factor; WJ: Wharton's jelly; WJMSCs: Wharton's jelly-derived mesenchymal stem cells; XF: Xeno-free.

\section{Competing interests}

The authors declare that they have no competing interests.

\section{Authors' contributions}

MCC participated in cell culture experiments, differentiation, histochemistry, molecular biology and Matrigel assays, and performed statistical data analysis. MAP participated in cell culture experiments, differentiation, molecular biology and Matrigel assays, and performed flow cytometry sample preparation and statistical data analysis. AR participated in cell culture experiments, differentiation, histochemistry and MTT assays, and performed statistical data analysis. LES performed flow cytometry data acquisition and statistical data analysis. Gl collected the umbilical cords, performed virology testing, and critically revised the manuscript. MLP participated in experiments, designed and coordinated the study, interpreted the data, wrote the manuscript, and gave final approval for manuscript publication. All authors read and approved the final manuscript.

\section{Authors' information}

MLP, Ph.D. is the leader of the Angiogenesis and Cardiovascular Remodeling Group at the Institute of Cellular Biology and Pathology "Nicolae Simionescu" in Bucharest and is a founding member of the Romanian Society for Developmental Biology. MLP coordinates national and international projects, including FP7, in the field of adult stem and progenitor cells, with a focus on cellular and molecular mechanisms of vasculogenesis and cardiovascular regeneration. 


\section{Acknowledgements}

This work was supported by the Romanian Ministry of Education and Research PNCDI-II grant No. 106/2010-2013 (MCC, AR, MLP), European Union FP7 grant No. 245691/2010-2013 (MCC, MAP, AR, MLP), POSDRU/89/1.5/S/ 60746 program from European Social Fund (LES) and "CARDIOPRO" ERDF project No. 143/2009-2012 - co-financed investment in RTDI for competitiveness (MCC, MAP, AR, MLP). We are grateful to STEMCELL Technologies ${ }^{\mathrm{TM}}$ Inc., Vancouver, BC, Canada for gratefully providing the XF and differentiation media for MSCs. We are also grateful to Dr. Virginia Lazar for support with umbilical cord sample collection and to Dr. Tomo Saric for providing the NUFF1 human fibroblast cell line.

\section{Author details}

${ }^{1}$ Angiogenesis and Cardiovascular Remodeling Group, Department of Regenerative Medicine, Institute of Cellular Biology and Pathology "Nicolae Simionescu" of the Romanian Academy, 8 B.P. Hasdeu Str., 050568, Bucharest, Romania. ${ }^{2}$ Department of Molecular Cell Biology, Institute of Biochemistry of the Romanian Academy, 296 Splaiul Independentei, 060031, Bucharest, Romania. ${ }^{3}$ Department of Obstetrics and Gynecology, Clinical Hospital "Dr. Ioan Cantacuzino", 5-7 Ion Movila Str., 020000, Bucharest, Romania.

Received: 11 March 2013 Revised: 13 June 2013

Accepted: 8 July 2013 Published: 11 July 2013

\section{References}

1. Bongso A, Fong CY: The therapeutic potential, challenges and future clinical directions of stem cells from the Wharton's jelly of the human umbilical cord. Stem Cell Rev 2013, 9:226-240.

2. Troyer DL, Weiss ML: Wharton's jelly-derived cells are a primitive stromal cell population. Stem Cells 2008, 26:591-599.

3. Can A, Karahuseyinoglu S: Concise review: human umbilical cord stroma with regard to the source of fetus-derived stem cells. Stem Cells 2007, 25:2886-2895.

4. Weiss ML, Anderson C, Medicetty S, Seshareddy KB, Weiss RJ, VanderWerff I, Troyer D, McIntosh KR: Immune properties of human umbilical cord Wharton's jelly-derived cells. Stem Cells 2008, 26:2865-2874.

5. La Rocca G, Lo IM, Corsello T, Corrao S, Farina F, Anzalone R: Human Wharton's jelly mesenchymal stem cells maintain the expression of key immunomodulatory molecules when subjected to osteogenic, adipogenic and chondrogenic differentiation in vitro: new perspectives for cellular therapy. Curr Stem Cell Res Ther 2013, 8:100-113.

6. Fong CY, Chak LL, Biswas A, Tan JH, Gauthaman K, Chan WK, Bongso A: Human Wharton's jelly stem cells have unique transcriptome profiles compared to human embryonic stem cells and other mesenchymal stem cells. Stem Cell Rev 2011, 7:1-16.

7. Wang HS, Hung SC, Peng ST, Huang CC, Wei HM, Guo YJ, Fu YS, Lai MC, Chen CC: Mesenchymal stem cells in the Wharton's jelly of the human umbilical cord. Stem Cells 2004, 22:1330-1337.

8. Batsali AK, Kastrinaki MC, Papadaki HA, Pontikoglou C: Mesenchymalstem cells derived from Wharton's jelly of the umbilical cord: biological properties and emerging clinical applications. Curr Stem Cell Res Ther 2012, 8:144-155.

9. Wu KH, Sheu JN, Wu HP, Tsai C, Sieber M, Peng CT, Chao YH: Cotransplantation of umbilical cord-derived mesenchymal stem cells promote hematopoietic engraftment in cord blood transplantation: a pilot study. Transplantation 2013, 95:773-777.

10. Anzalone R, Lo lacono M, Corrao S, Magno F, Loria T, Cappello F, Zummo G, Farina F, La Rocca G: New emerging potentials for human Wharton's jelly mesenchymal stem cells: immunological features and hepatocyte-like differentiative capacity. Stem Cells Dev 2010, 19:423-438.

11. Fong CY, Richards M, Manasi N, Biswas A, Bongso A: Comparative growth behaviour and characterization of stem cells from human Wharton's jelly. Reprod Biomed Online 2007, 15:708-718.

12. Nekanti U, Rao VB, Bahirvani AG, Jan M, Totey S, Ta M: Long-term expansion and pluripotent marker array analysis of Wharton's jellyderived mesenchymal stem cells. Stem Cells Dev 2010, 19:117-130.

13. Chen MY, Lie PC, Li ZL, Wei X: Endothelial differentiation of Wharton's jelly-derived mesenchymal stem cells in comparison with bone marrowderived mesenchymal stem cells. ExpHematol 2009, 37:629-640.

14. Abu Kasim NH, Govindasamy V, Gnanasegaran N, Musa S, Pradeep PJ, Srijaya TC, Aziz ZA: Unique molecular signatures influencing the biological function and fate of post-natal stem cells isolated from different sources. J Tissue EngRegen Med; 2012 [Epub ahead of print.].

15. La Rocca G, Corrao S, Lo lacono M, Corsello T, Farina F, Anzalone R: Novel immunomodulatory markers expressed by human WJ-MSC: an updated review in regenerative and reparative medicine. Open Tissue Eng Regen Med J 2012, 5:50-58.

16. Alaminos M, Pérez-Köhler B, Garzón I, García-Honduvilla N, Romero B, Campos A, Buján J: Transdifferentiation potentiality of human Wharton's jelly stem cells towards vascular endothelial cells. J Cell Physiol 2010, 223:640-647.

17. Wang SH, Lin SJ, Chen YH, Lin FY, Shih JC, Wu CC, Wu HL, Chen YL: Late outgrowth endothelial cells derived from Wharton jelly in human umbilical cord reduce neointimal formation after vascular injury: involvement of pigment epithelium-derived factor. Arterioscler Thromb Vasc Biol 2009, 29:816-822.

18. Kadam SS, Tiwari S, Bhonde RR: Simultaneous isolation of vascular endothelial cells and mesenchymal stem cells from the human umbilical cord. In Vitro Cell Dev Biol Anim 2009, 45:23-27.

19. Wu KH, Zhou B, Lu SH, Feng B, Yang SG, Du WT, Gu DS, Han ZC, Liu YL: In vitro and in vivo differentiation of human umbilical cord derived stem cells into endothelial cells. J Cell Biochem 2007, 100:608-616.

20. De Bruyn C, Najar M, Raicevic G, Meuleman N, Pieters K, Stamatopoulos B, Delforge A, Bron D, Lagneaux L: A rapid, simple, and reproducible method for the isolation of mesenchymal stromal cells from Wharton's jelly without enzymatic treatment. Stem Cells Dev 2011, 20:547-557.

21. Pereira WC, Khushnooma I, Madkaikar M, Ghosh K: Reproducible methodology for the isolation of mesenchymal stem cells from human umbilical cord and its potential for cardiomyocyte generation. J Tissue Eng Regen Med 2008, 2:394-399.

22. Weiss ML, Medicetty S, Bledsoe AR, Rachakatla RS, Choi M, Merchav S, Luo $Y$, Rao MS, Velagaleti G, Troyer D: Human umbilical cord matrix stem cells: preliminary characterization and effect of transplantation in a rodent model of Parkinson's disease. Stem Cells 2006, 24:781-792.

23. Seshareddy K, Troyer D, Weiss ML: Method to isolate mesenchymal-like cells from Wharton's jelly of umbilical cord. Methods Cell Biol 2008, 86:101-119.

24. Chase LG, Yang S, Zachar V, Yang Z, Lakshmipathy U, Bradford J, Boucher SE, Vemuri MC: Development and characterization of a clinically compliant xeno-free culture medium in good manufacturing practice for human multipotentmesenchymal stem cells. Stem Cells Transl Med 2012, 1:750-758.

25. Patrikoski M, Juntunen M, Boucher S, Campbell A, Vemuri MC, Mannerstrom $B$, Miettinen S: Development of fully defined xeno-free culture system for the preparation and propagation of cell therapy-compliant human adipose stem cells. Stem Cell Res Ther 2013, 4:27.

26. Gottipamula S, Muttigi MS, Chaansa S, Ashwin KM, Priya N, Kolkundkar U, Sundar Raj S: Majumdar AS. Seetharam RN: Large-scale expansion of pre-isolated bone marrow mesenchymal stromal cells in serum-free conditions. J Tissue Eng Regen Med; 2013 [Epub ahead of print.].

27. Spees JL, Gregory CA, Singh H, Tucker HA, Peister A, Lynch PJ, Hsu SC, Smith J, Prockop DJ: Internalized antigens must be removed to prepare hypoimmunogenicmesenchymal stem cells for cell and gene therapy. Mol Ther 2004, 9:747-756.

28. Santos F, Andrade PZ, Abecasis MM, Gimble JM, Chase LG, Campbell AM, Boucher S, Vemuri MC, Silva CL, Cabral JM: Toward a clinical-grade expansion of mesenchymal stem cells from human sources: a microcarrier-based culture system under xeno-free conditions. Tissue Eng Part C Methods 2011, 17:1201-1210.

29. Hou T, Xu J, Wu X, Xie Z, Luo F, Zhang Z, Zeng L: Umbilical cord Wharton's jelly: a new potential cell source of mesenchymal stromal cells for bone tissue engineering. Tissue Eng Part A 2009, 15:2325-2334.

30. Wang L, Tran I, Seshareddy K, Weiss ML, Detamore MS: A comparison of human bone marrow-derived mesenchymal stem cells and human umbilical cord-derived mesenchymal stromal cells for cartilage tissue engineering. Tissue Eng Part A 2009, 15:2259-2266.

31. Wang L, Ott L, Seshareddy K, Weiss ML, Detamore MS: Musculoskeletal tissue engineering with human umbilical cord mesenchymal stromal cells. Regen Med 2011, 6:95-109.

32. Conconi MT, Burra P, Di Liddo R, Calore C, Turetta M, Bellini S, Bo P, Nussdorfer GG, Parnigotto PP: CD105(+) cells from Wharton's jelly show in vitro and in vivo myogenic differentiative potential. Int J Mol Med 2006, 18:1089-1096. 
33. Gartner A, Pereira T, Armada-da-Silva PA, Amorim I, Gomes R, Ribeiro J, Franca ML, Lopes C, Porto B, Sousa R, Bombaci A, Ronchi G, Fregnan F, Varejao AS, Luis AL, Geuna S, Mauricio AC: Use of poly(DL-lactide-epsilon-caprolactone) membranes and mesenchymal stem cells from the Wharton's jelly of the umbilical cord for promoting nerve regeneration in axonotmesis: in vitro and in vivo analysis. Differentiation 2012, 84:355-365.

34. Tsai PC, Fu TW, Chen YM, Ko TL, Chen TH, Shih YH, Hung SC, Fu YS: The therapeutic potential of human umbilical mesenchymal stem cells from Wharton's jelly in the treatment of rat liver fibrosis. Liver Transp/ 2009, 15:484-495

35. Anzalone R, Lo IM, Loria T, Di SA, Giannuzzi P, Farina F, La Rocca G: Wharton's jelly mesenchymal stem cells as candidates for beta cells regeneration: extending the differentiative and immunomodulatory benefits of adult mesenchymal stem cells for the treatment of type 1 diabetes. Stem Cell Rev 2011, 7:342-363.

36. Schmidt D, Mol A, Odermatt B, Neuenschwander S, Breymann C, Gössi M, Genoni M, Zund G, Hoerstrup SP: Engineering of biologically active living heart valve leaflets using human umbilical cord-derived progenitor cells. Tissue Eng 2006, 12:3223-3232.

37. Chan RW, Rodriguez ML, McFetridge PS: The human umbilical vein with Wharton's jelly as an allogeneic, acellular construct for vocal fold restoration. Tissue Eng Part A 2009, 15:3537-3546.

38. Dominici M, Le Blanc K, Mueller I, Slaper-Cortenbach I, Marini F, Krause D, Deans R, Keating A, Prockop D, Horwitz E: Minimal criteria for defining multipotentmesenchymal stromal cells. The International Society for Cellular Therapy position statement. Cytotherapy 2006, 8:315-317.

39. Alhadlaq A, Tang M, Mao J: Engineered adipose tissue from human mesenchymal stem cells maintains predefined shape and dimension: implications in soft tissue augmentation and reconstruction. Tissue Eng 2005, 11:556-566.

40. Lugus JJ, Chung YS, Mills JC, Kim SI, Grass J, Kyba M, Doherty JM, Bresnick $\mathrm{EH}$, Choi K: GATA2 functions at multiple steps in hemangioblast development and differentiation. Development 2007, 134:393-405.

41. Eriksson U, Alitalo K: VEGF receptor 1 stimulates stem-cell recruitment and new hope for angiogenesis therapies. Nat Med 2002, 8:775-777.

42. Miwa H, Hashimoto Y, Tensho K, Wakitani S, Takagi M: Xeno-free proliferation of human bone marrow mesenchymal stem cells. Cytotechnology 2012, 64:301-308.

43. Chevallier N, Anagnostou F, Zilber S, Bodivit G, Maurin S, Barrault A, Bierling $\mathrm{P}$, Hernigou $\mathrm{P}$, Layrolle $\mathrm{P}$, Rouard $\mathrm{H}$ : Osteoblastic differentiation of human mesenchymal stem cells with platelet lysate. Biomaterials 2010, 31:270-278

44. Hsieh JY, Fu YS, Chang SJ, Tsuang YH, Wang HW: Functional module analysis reveals differential osteogenic and stemness potentials in human mesenchymal stem cells from bone marrow and Wharton's jelly of umbilical cord. Stem Cells Dev 2010, 19:1895-1910.

45. Yang T, Chen GH, Xue SL, Qiao M, Liu HW, Tian H, Qiao SM, Chen F, Chen ZZ, Sun AN, Wu DP: [Comparison of the biological characteristics of serum-free and fetal bovine serum-contained medium cultured umbilical cord-derived mesenchymal stem cells]. ZhonghuaXue Ye XueZaZhi 2012, 33:715-719.

46. Simoes IN, Boura JS, dos Santos F, Andrade PZ, Cardoso CM, Gimble JM, da Silva CL, Cabral JM: Human mesenchymal stem cells from the umbilical cord matrix: successful isolation and ex vivo expansion using serum/xeno-free culture media. Biotechnol J 2013, 8:448-458.

47. Wagner W, Feldmann RE Jr, Seckinger A, Maurer MH, Wein F, Blake J, Krause U, Kalenka A, Bürgers HF, Saffrich R, Wuchter P, Kuschinsky W, Ho AD: The heterogeneity of human mesenchymal stem cell preparations-evidence from simultaneous analysis of proteomes and transcriptomes. Exp Hematol 2006, 34:536-548.

48. Wagner W, Horn P, Castoldi M, Diehlmann A, Bork S, Saffrich R, Benes V, Blake J, Pfister S, Eckstein V, Ho AD: Replicative senescence of mesenchymal stem cells: a continuous and organized process. PLOS One 2008, 3:e2213.

49. Pevsner-Fischer M, Levin S, Zipori D: The origins of mesenchymal stromal cell heterogeneity. Stem Cell Rev 2011, 7:560-568.

50. Majore I, Moretti $\mathrm{P}$, Hass R, Kasper C: Identification of subpopulations in mesenchymal stem cell-like cultures from human umbilical cord. Cell Commun Signal 2009, 7:6

51. Zhu H, Mitsuhashi N, Klein A, Barsky LW, Weinberg K, Barr ML, Demetriou A, Wu GD: The role of the hyaluronan receptor CD44 in mesenchymal stem cell migration in the extracellular matrix. Stem Cells 2006, 24:928-935.
52. Phinney DG: Biochemical heterogeneity of mesenchymal stem cell populations: clues to their therapeutic efficacy. Cell Cycle 2007, 6:2884-2889.

53. Digirolamo CM, Stokes D, Colter D, Phinney DG, Class R, Prockop DJ: Propagation and senescence of human marrow stromal cells in culture: a simple colony-forming assay identifies samples with the greatest potential to propagate and differentiate. Br J Haematol 1999, 107:275-281.

54. Requicha JF, Viegas CA, Albuquerque CM, Azevedo JM, Reis RL, Gomes ME: Effect of anatomical origin and cell passage number on the stemness and osteogenic differentiation potential of canine adipose-derived stem cells. Stem Cell Rev 2012, 8:1211-1222.

55. Wall ME, Bernacki SH, Loboa EG: Effects of serial passaging on the adipogenic and osteogenic differentiation potential of adipose-derived human mesenchymal stem cells. Tissue Eng 2007, 13:1291-1298.

56. Yu S, Long J, Yu J, Du J, Ma P, Ma Y, Yang D, Fan Z: Analysis of differentiation potentials and gene expression profiles of mesenchymal stem cells derived from periodontal ligament and Wharton's jelly of the umbilical cord. Cells Tissues Organs 2013, 197:209-223.

57. Kim MJ, Shin KS, Jeon JH, Lee DR, Shim SH, Kim JK, Cha DH, Yoon TK, Kim GJ: Human chorionic-plate-derived mesenchymal stem cells and Wharton's jelly-derived mesenchymal stem cells: a comparative analysis of their potential as placenta-derived stem cells. Cell Tissue Res 2011 346:53-64.

58. Huang S, Wang S, Bian C, Yang Z, Zhou H, Zeng Y, Li H, Han Q, Zhao RC: Upregulation of miR-22 promotes osteogenic differentiation and inhibits adipogenic differentiation of human adipose tissue-derived mesenchymal stem cells by repressing HDAC6 protein expression. Stem Cells Dev 2012, 21:2531-2540.

59. Kuo HC, Chiu CC, Chang WC, Sheen JM, Ou CY, Kuo HC, Chen RF, Hsu TY, Chang JC, Hsaio CC, Wang FS, Huang CC, Huang HY, Yang KD: Use of proteomic differential displays to assess functional discrepancies and adjustments of human bone marrow- and Wharton jelly-derived mesenchymal stem cells. J Proteome Res 2011, 10:1305-1315.

60. Trochon V, Mabilat C, Bertrand P, Legrand Y, Smadja-Joffe F, Soria C, Delpech B, Lu H: Evidence of involvement of CD44 in endothelial cell proliferation, migration and angiogenesis in vitro. Int J Cancer 1996, 66:664-668.

61. Cao G, Savani RC, Fehrenbach M, Lyons C, Zhang L, Coukos G, Delisser HM: Involvement of endothelial CD44 during in vivo angiogenesis. Am J Pathol 2006, 169:325-336.

62. Choi KD, Vodyanik MA, Togarrati PP, Suknuntha K, Kumar A, Samarjeet F, Probasco MD, Tian S, Stewart R, Thomson JA, Slukvin II: Identification of the hemogenic endothelial progenitor and its direct precursor in human pluripotent stem cell differentiation cultures. Cell Rep 2012, 2:553-567.

63. Kinnaird T, Stabile E, Burnett MS, Shou M, Lee CW, Barr S, Fuchs S, Epstein SE: Local delivery of marrow-derived stromal cells augments collateral perfusion through paracrine mechanisms. Circulation 2004, 109:1543-1549.

64. Kondo K, Shintani S, Shibata R, Murakami H, Murakami R, Imaizumi M, Kitagawa $Y$, Murohara T: Implantation of adipose-derived regenerative cells enhances ischemia-induced angiogenesis. Arterioscler Thromb Vasc Biol 2009, 29:61-66.

65. Choi M, Lee HS, Naidansaren $\mathrm{P}, \mathrm{Kim} \mathrm{H}-\mathrm{K}, \mathrm{O}$ E, Cha J-H, Ahn H-Y, Yang PI, Shin J-C, Joe YA: Proangiogenic features of Wharton's jelly-derived mesenchymal stromal/stem cells and their ability to form functional vessels. Int J Biochem Cell Biol 2012, 45:560-570.

66. De Kock J, Najar M, Bolleyn J, Al Battah F, Rodrigues RM, Buyl K, Raicevic G, Govaere O, Branson S, Meganathan K, Gaspar JA, Roskams T, Sachinidis A, Lagneaux L, Vanhaecke T, Rogiers V: Mesoderm-derived stem cells: the link between the transcriptome and their differentiation potential. Stem Cells Dev 2012, 21:3309-3323.

67. Liang J, Wu S, Zhao H, Li SL, Liu ZX, Wu J, Zhou L: Human umbilical cord mesenchymal stem cells derived from Wharton's jelly differentiate into cholinergic-like neurons in vitro. Neurosci Lett 2013, 532:59-63.

doi:10.1186/scrt232

Cite this article as: Corotchi et al:: Isolation method and xeno-free culture conditions influence multipotent differentiation capacity of human Wharton's jelly-derived mesenchymal stem cells. Stem Cell Research \& Therapy 2013 4:81. 